\title{
Researches of Epigenetic Epidemiology for Infections and Radiation as Carcinogen
}

\author{
Jong-Myon Bae \\ Department of Preventive Medicine, Jeju National University School of Medicine, Jeju, Korea
}

In recent years, a number of studies have been reported on the various types of cancer arising from epigenetic alterations, including reports that these epigenetic alterations occur as a result of radiation exposure or infection. Thyroid cancer and breast cancer, in particular, have high cancer burden, and it has been confirmed that radiation exposure or onco-viral infection are linked to increased risk of development of these two types of cancer, respectively. Thus, the environment-epigenetic alteration-cancer occurrence (EEC) hypothesis has been suggested. This paper reviews the trends in research supporting this hypothesis for radiation exposure and oncoviral infection. If more evidences accumulate for the EEC hypothesis from future research, those findings may greatly aid in the prevention, early diagnosis, treatment, and prognosis of the thyroid cancer and breast cancer.

Key words: Carcinogenesis, Epigenomics, DNA methylation, Infection, Radiation

\section{INTRODUCTION}

Thyroid cancer is the most common type of cancer for Korean, while breast cancer is the only cancer among primary site cancers evaluated by Korea's National Cancer Screening Program that shows an increased incidence each year [1]. Thus, there is an urgent need to improve the prevention programs that can reduce the incidence rate of thyroid cancer and breast cancer.

In order to prevent specific cancers, various carcinogens that increase the risk of those cancers need to be identified and controlled. Smith et al. [2] summarized and suggested the mechanisms by which the carcinogens cause various types of

Received: March 16, 2018 Accepted: June 13, 2018

Corresponding author: Jong-Myon Bae, MD, PhD

Department of Preventive Medicine, Jeju National University School

of Medicine, 102 Jejudaehak-ro, Jeju 63243, Korea

E-mail: jmbae@jejunu.ac.kr

This is an Open Access article distributed under the terms of the Creative Commons Attribution Non-Commercial License (http://creativecommons.org/licenses/by$\mathrm{nc} / 4.0 /$ ) which permits unrestricted non-commercial use, distribution, and reproduction in any medium, provided the original work is properly cited. cancer. One of the suggested mechanisms was carcinogenesis resulting from epigenetic alterations.

Epigenetic alterations are heritable changes in gene expression that do not affect the DNA sequence [3], and cell molecular changes include DNA methylation, histone modifications, and microRNAs [4,5]. In 1983, Feinberg and Vogelstein [6] proposed the possibility of cancer development resulting from epigenetic alterations. Since then, this idea has been applied to various types of cancer [7]. It is now believed that cancer develops not only from genomic changes but also from epigenetic alterations (Table S1).

As of the year-end in 2015, Verma [7] reviewed the studies that investigated the association between epigenetic alteration and carcinogens, and then proposed infectious agents, radiation, and toxic substances are key environmental factors that may cause epigenetic alteration. According to Verma [7], epigenetic alterations occur due to environmental factors, which lead to cancer development, establishing a sort of loop. This suggests the environment-epigenetic alteration-cancer (EEC) hypothesis (Figure 1).

This paper examines the trends in research that supports 


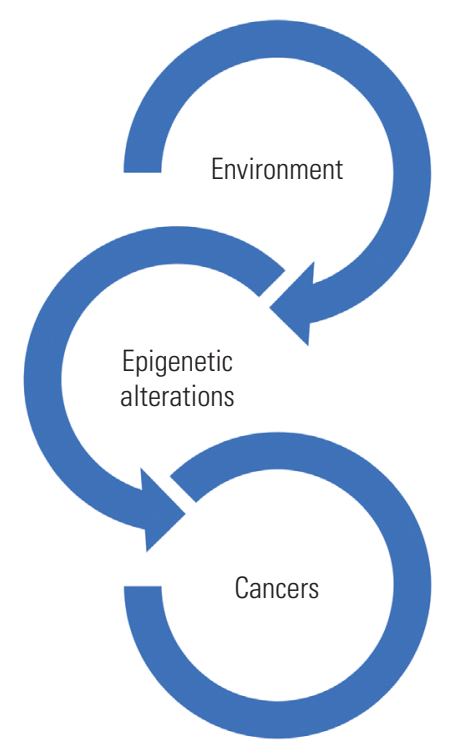

Figure 1. A chain of environment such as environment (including infection or radiation), epigenetic alterations and cancers.

the EEC hypothesis with a focus on the studies related to thyroid cancer and breast cancer development caused by two environmental factors, radiation and infectious agents, and aims to provide research directions and topics involving epigenomes in these two types of cancer, which have high burdens.

\section{RADIATION- EPIGENETIC ALTERATION - (THYROID) CANCER OCCURRENCE HYPOTHESIS}

In addition to thyroid cancer, breast cancer and leukemia are primary cancers known to be caused by exposure to radiation $[8,9]$. There are a number of epidemiological findings from the studies on the survivors of the nuclear disasters in Japan and Chernobyl that support acute radiation exposure at high concentration is associated with increased risk of thyroid cancer development $[8,10]$.

Genetic mutations in thyroid cancer may be divided into the following two mutations: (1) BRAF/RAS point mutation and (2) RET/PTC chromosomal rearrangement [11]. It has been reported that compared to tumor cells of sporadic thyroid cancer, thyroid cancer cells of nuclear disaster survivors showed higher cases of RET/PTC chromosomal rearrangement mutation than the BRAF/RAS point mutation. The number of cases for the RET/PTC chromosomal rearrangement increased as the level of radiation exposure increased [10,12]. Based on these findings, it would be possible to infer a specific carcinogenesis for each cases of cancer by examining the pattern of genetic changes [13].

Vu-Phan and Koenig [11] reviewed the research findings on epigenetic alterations in thyroid cancer. However, the number of epigenetic studies are less than of researches identifying genetic changes. Furthermore, it is very limited to see study findings that support the hypothesis of radiation-induced epigenetic alterations lead to thyroid cancer development. Thus, the research proposal for the EEC hypothesis is based on the following three grounds.

First, Bird [14] proposed to redefine the epigenetics as 'the structural adaptation of chromosomal regions' in 2007. This was due to the fact that the key mutations of the radiation-induced thyroid cancer are chromosomal rearrangements [10, 12]. In other words, it is necessary to examine epigenetic alterations in radiation-induced thyroid cancer.

Second, identifying some specific patterns of epigenetic alterations according to radiation exposure may help predict carcinogens, which in turn can provide clues to the controversy on the association between chronic exposure to low concentration of radiation and thyroid cancer [9].

Third, if gathering more evidences supporting the hypothesis that epigenetic alterations lead to thyroid cancer development, it would be possible to provide early cancer diagnosis, personalized cancer treatment, and cancer prevention to nuclear plant workers [11].

\section{INFECTION- EPIGENETIC ALTERATION - (BREAST) CANCER OCCURRENCE HYPOTHESIS}

Okada [15] summarized the infectious agents related to each of primary site cancers through classic epidemiology and is explaining this using the mechanism of inflammation-related carcinogenesis. It has been reported that chronic inflammation caused by Helicobacter pylori (H. pylori) and hepatitis virus lead to aberrant DNA methylation [16]. This suggests that chronic inflammation caused by infectious agents result in epigenetic alteration, leading to carcinogenesis $[16,17]$. These successive steps to cancer development could be explained by the EEC hypothesis. In other words, a number of studies are applying the EEC hypothesis and investigating the cancers that have proven associations with infectious agents, such as 
H. pylori infection and stomach cancer, human papillomavirus (HPV) infection and cervical cancer, and hepatitis $B / C$ virus and liver cancer [18].

In 2008, Lo and Sukumar [19] reviewed the findings on the mechanism of breast cancer carcinogenesis resulting from epigenetic alterations and claimed that 'breast cancer carcinogenesis involves genetic and epigenetic alterations that cause aberrant gene function'. It has been reported that, in addition to being the key mechanism of breast cancer development, epigenetic alterations determine the histological type and are involved in ER/PR hormone receptors and cancer drug resistance $[4,20]$.

Moreover, some systematic reviews showed Epstein-Barr virus (EBV), HPV, and human mammary tumor virus (HMTV) infections increase the risk of breast cancer development by 3.84 times (95\% confidence interval [Cl], 2.24 to 6.58$)$ [21], 4.02 times ( $95 \% \mathrm{Cl}, 2.42$ to 6.68$)$ [22], and 8.37 times $(95 \% \mathrm{Cl}, 2.29$ to 23.39) [23], respectively.

There have been, however, only a limited number of studies on the EEC hypothesis of breast cancer, which suggests that onco-viral infection causes epigenetic alterations, resulting in breast cancer development. The aforementioned cell molecular findings that show epigenetic alteration leads to breast cancer development and classic epidemiologic findings that show EBV, HPV, and HMTV increase the risk of breast cancer development provide enough justification to apply EEC hypothesis to the breast cancer development. This proposal is based on the following three grounds.

First, a systematic review showed that EBV infection increases stomach cancer development by 3.40 times $(95 \% \mathrm{Cl}, 1.78$ to 6.51) [24], and the evidence supporting the association between epigenetic alteration and stomach cancer are being established [16]. Moreover, systematic reviews showing that HPV and HMTV infections, in addition to EBV infection, are linked to increased risk of breast cancer development have been reported [21-23]. Thus, there is a need for more research on the epigenetics of the oncovirus induced breast cancer development.

Second, the incidence rate of breast cancer in Korean women is the highest between the ages of 45-49 and decreases thereafter. This unique epidemiologic characteristic has continued since the national cancer registry project has started. This pattern can be explained by infections $[25,26]$. It has been known that liver cancer develops 10-30 years after hepatitis B virus infection [27], and, in general, cancer develops 14-40 years after oncovirus infections [28]. Thus, the time of breast cancer development may be linked to the infection at puberty, at which Korean women begin sexual activities.

Third, a vaccine for HPV has been developed, and adolescent women students are given the vaccination with the purpose of cervical cancer prevention. Based on the EEC hypothesis, this program may result in lowering breast cancer incidence [25].

\section{CONCLUSIONS AND SUGGESTIONS}

If a specific cancer due to epigenetic alterations occurs, it may be possible to provide early diagnosis, personalized therapy, and prevention programs for those cancers $[16,29]$. If there are more evidence supporting the hypothesis that thyroid cancer and breast cancer, two types of cancer with highest cancer burden in Korea, are caused by radiation- and infection-induced epigenetic alterations, an active prevention strategy may be developed.

Furthermore, as infections have been estimated to be associated with approximately $20 \%$ of cancers worldwide, $12 \%$ of which is caused by oncovirus [30], researches on the mechanisms of carcinogenesis based on the EEC hypothesis may greatly contribute to the prevention, early diagnosis, treatment, and prognosis of the infection-induced cancers.

\section{ACKNOWLEDGEMENTS}

This research was supported by the 2018 scientific promotion program funded by Jeju National University.

\section{CONFLICT OF INTEREST}

The author has no conflicts of interest associated with the material presented in this paper.

\section{SUPPLEMENTAL MATERIALS}

Supplementary Material 1: Table S1 is available at https:// www.jpmph.org/.

\section{ORCID}

Jong-Myon Bae http://orcid.org/0000-0003-3080-7852 


\section{REFERENCES}

1. Jung KW, Won YJ, Oh CM, Kong HJ, Lee DH, Lee KH, et al. Cancer statistics in Korea: incidence, mortality, survival, and prevalence in 2014. Cancer Res Treat 2017;49(2):292-305.

2. Smith MT, Guyton KZ, Gibbons CF, Fritz JM, Portier CJ, Rusyn I, et al. Key characteristics of carcinogens as a basis for organizing data on mechanisms of carcinogenesis. Environ Health Perspect 2016;124(6):713-721.

3. Slack JM. Conrad Hal Waddington: the last renaissance biologist? Nat Rev Genet 2002;3(11):889-895.

4. Huang Y, Nayak S, Jankowitz R, Davidson NE, Oesterreich S. Epigenetics in breast cancer: what's new? Breast Cancer Res 2011;13(6):225.

5. Bae JM. Interpretation of the hygiene and microflora hypothesis for allergic diseases through epigenetic epidemiology. Epidemiol Health 2018;40:e2018006.

6. Feinberg AP, Vogelstein B. Hypomethylation distinguishes genes of some human cancers from their normal counterparts. Nature 1983;301(5895):89-92.

7. Verma M. Genome-wide association studies and epigenomewide association studies go together in cancer control. Future Oncol 2016;12(13):1645-1664.

8. Moysich KB, Menezes RJ, Michalek AM. Chernobyl-related ionising radiation exposure and cancer risk: an epidemiological review. Lancet Oncol 2002;3(5):269-279.

9. Barcellos-Hoff MH, Nguyen DH. Radiation carcinogenesis in context: how do irradiated tissues become tumors? Health Phys 2009;97(5):446-457.

10. Leeman-Neill RJ, Brenner AV, Little MP, Bogdanova TI, Hatch M, Zurnadzy LY, et al. RET/PTC and PAX8/PPARY chromosomal rearrangements in post-Chernobyl thyroid cancer and their association with iodine-131 radiation dose and other characteristics. Cancer 2013;119(10):1792-1799.

11. Vu-Phan D, Koenig RJ. Genetics and epigenetics of sporadic thyroid cancer. Mol Cell Endocrinol 2014;386(1-2):55-66.

12. Hamatani K, Eguchi H, Ito R, Mukai M, Takahashi K, Taga M, et al. RET/PTC rearrangements preferentially occurred in papillary thyroid cancer among atomic bomb survivors exposed to high radiation dose. Cancer Res 2008;68(17):7176-7182.

13. Bae JM. Thyroid cancer: we need a carcinogen-specific genome study. J Korean Med Sci 2015;30(12):1920-1921.

14. Bird A. Perceptions of epigenetics. Nature 2007;447(7143): 396-398.

15. Okada F. Inflammation-related carcinogenesis: current find- ings in epidemiological trends, causes and mechanisms. Yonago Acta Med 2014;57(2):65-72.

16. Hattori $\mathrm{N}$, Ushijima T. Epigenetic impact of infection on carcinogenesis: mechanisms and applications. Genome Med 2016; 8(1):10.

17. Asada K, Nakajima T, Shimazu T, Yamamichi N, Maekita T, Yokoi $C$, et al. Demonstration of the usefulness of epigenetic cancer risk prediction by a multicentre prospective cohort study. Gut 2015;64(3):388-396.

18. de Martel C, Ferlay J, Franceschi S, Vignat J, Bray F, Forman D, et al. Global burden of cancers attributable to infections in 2008: a review and synthetic analysis. Lancet Oncol 2012; 13(6):607-615.

19. Lo PK, Sukumar S. Epigenomics and breast cancer. Pharmacogenomics 2008;9(12):1879-1902.

20. Blair LP, Yan Q. Epigenetic mechanisms in commonly occurring cancers. DNA Cell Biol 2012;31 Suppl 1:S49-S61.

21. Bae JM, Kim EH. Epstein-Barr virus infection and risk of breast cancer: an adaptive meta-analysis for case-control studies. Arch Clin Infect Dis 2016;11(3):e34806.

22. Bae JM, Kim EH. Human papillomavirus infection and risk of breast cancer: a meta-analysis of case-control studies. Infect Agent Cancer 2016;11:14.

23. Bae JM, Kim EH. Human mammary tumor virus (HMTV) infection and risk of human breast cancer: an adaptive meta-analysis for case-control studies. Res Rev J Microbiol Biotechnol 2016;5(1):78-85.

24. Bae JM, Kim EH. Epstein-Barr virus and gastric cancer risk: a meta-analysis with meta-regression of case-control studies. J Prev Med Public Health 2016;49(2):97-107.

25. Bae JM. Two hypotheses of dense breasts and viral infection for explaining incidence of breast cancer by age group in Korean women. Epidemiol Health 2014;36:e2014020.

26. Cho HJ, Joo WH, Kim YN, Bae JM, Nam CM. Cohort effects of female breast cancer incidence in Korea. J Health Inform Stat 2014;39(2):32-43 (Korean).

27. Saitta C, Tripodi G, Barbera A, Bertuccio A, Smedile A, Ciancio A, et al. Hepatitis $B$ virus (HBV) DNA integration in patients with occult HBV infection and hepatocellular carcinoma. Liver Int 2015;35(10):2311-2317.

28. Zur Hausen $\mathrm{H}$. The search for infectious causes of human cancers: where and why. Virology 2009;392(1):1-10.

29. Boumber Y, Issa JP. Epigenetics in cancer: what's the future? Oncology (Williston Park) 2011;25(3):220-226.

30. Mui UN, Haley CT, Tyring SK. Viral oncology: molecular biology and pathogenesis. J Clin Med 2017;6(12):E111. 